\title{
DOGMAS E PRAZERES: O DISCURSO MORAL RELIGIOSO EM TORNO DA VIVÊNCIA DA SEXUALIDADE NO OCIDENTE MEDIEVAL
}

\author{
Viviane Caminhas SANTANA ${ }^{1}$ \\ Universidade Estadual de Montes Claros/Unimontes \\ vivisantana15@yahoo.com.br
}

Resumo: Este estudo tem como propósito, fazer uma abordagem sobre as vivências do amor e da sexualidade nos primeiros séculos da Idade Média Ocidental, buscando uma compreensão de como ou em que medida o Cristianismo rompe com a vivência do amor e da sexualidade nos tempos antigos, construindo uma nova mentalidade cristã contrária aos preceitos clássicos. O desenho adotado para o alcance dos objetivos propostos foi o de uma investigação de cunho exploratório, embasada nos estudos de autores como Pedro Paulo Funari, Jacques Lê Goff, Hilário Franco Junior, Lourdes Conde Feitosa, Michel Foucault e outros. A investigação procura analisar o problema a partir também da documentação produzida pelos primeiros concílios por meio de seus cânones, bem como por meio das encíclicas e dos documentos da Igreja Católica. A pesquisa revelou as inegáveis estratégias utilizadas pela Igreja como forma de romper com a sexualidade clássica, agora vista sob o prisma do erotismo, determinado pelos teólogos da Igreja.

Palavras-Chave: Sexualidade. Cristianismo. Idade Media. Antiguidade Clássica.

Abstract: This study aims, to make an approach to their experiences of love and sexuality in the early centuries of the Western Middle Ages, seeking an understanding of how or to what extent Christianity breaks with the experience of love and sexuality in ancient times, constructing a new Christian mentality contrary to classical precepts. The design adopted for achieving the proposed objectives was that of an exploratory research, based on studies by authors such as Pedro Paulo Funari, Jacques Le Goff, Hilary Franco Junior, Lourdes

\footnotetext{
${ }^{1}$ Mestranda em História Social pela Universidade Estadual de Montes Claros/ Unimontes.
} 
Conde Feitosa, Michel Foucault and others. The research seeks to analyze the problem as well as the documentation produced by the early councils through their canons as well as through the documents and encyclicals of the Catholic Church. The survey revealed the undeniable strategies used by the Church as a way to break with classical sexuality, now seen through the prism of eroticism determined by the theologians of the Church.

Keywords: Sexuality. Christianity. Middle Ages. Classical antiquity.

\section{Introdução}

A preocupação com abordagens até então consideradas irrelevantes passou a despertar, a partir das últimas décadas do século XX, um interesse cada vez maior por parte dos historiadores nas suas propostas de pesquisa. Novos temas, como o amor, a sexualidade, as emoções, as doenças, enfim, novos ou antigos objetos vistos por meio de novos olhares, têm sido alvos de um número crescente de investigações históricas, por meio dos mais variados enfoques. Tais mudanças devem-se às novas propostas apresentadas a partir da escola dos Annales, que finalmente possibilitou uma revolução metodológica, não só no ensino de história, mas também nas mais variadas pesquisas nesse campo. Seus fundadores, Marc Bloch e Lucien Febvre, ao lançarem, em 1929, a "Revista d'Histoire economique et sociale" proporcionaram à comunidade historiográfica novos métodos de trabalho, propondo novas fontes para investigações.

A história aumentou seu leque de fontes historiográficas, servindo-se de todos os meios para preencher as lacunas deixadas pelas fontes. Abriu ainda possibilidades de análises de fontes, de escrita, dando certa liberdade ao historiador para não se ater apenas aos documentos oficiais e seguir etapas metódicas para construção da história. "Os documentos não são mais ofícios, cartas, editais, textos explícitos sobre a intenção do sujeito, mas listas de preços, de salários, séries de certidão de batismo, óbito, casamento, nascimento, fontes notariais, contratos, testemunhos inventários" (REIS, 2000, 
p. 23). A história então passa a aceitar todos os documentos como vestígios da passagem do homem.

Partindo desse pressuposto, diante da ampliação de novas temáticas e objetos, o estudo da sexualidade como objeto da história passa a ganhar expressividade. Sobre este assunto, Feitosa considera que "esse repensar referências que contenham conotações sexuais é ainda algo muito recente e só há pouco tempo mostrou ser viável e produzir resultados consistentes, como ficou patente no caso da documentação material, romana" (FEITOSA, 2005, p. 43).

\section{Menino, quem foi seu mestre: as relações pederastas na Grécia antiga}

Um breve estudo acerca das relações pederastas na antiguidade grega tem muito a contribuir para se entender como pode ser pensada a sexualidade naquela sociedade.

$\mathrm{Na}$ Grécia antiga não existiam palavras para designar os termos "homossexualidade" e "heterossexualidade", pois a ideia de sexualidade é ainda uma construção cultural recente e inexistente no período. O termo mais utilizado para designar esse tipo de relação era a pederastia ${ }^{2}$ grega.

Sobre esse assunto Bremmer considera que:

Enquanto os homossexuais modernos muitas vezes ocupam uma posição marginal na sociedade e são normalmente considerados como efeminados, na Grécia, era a pederastia que propiciava acesso ao mundo da elite social; era apenas a relação pederasta que transformava o rapaz em um verdadeiro homem (BREMMER, 1995, p. 26).

\footnotetext{
${ }^{2}$ Segundo Jean Bremmer (1995), define-se pederastia por uma perversão em que ocorre relação sexual de homem com menino.
} 
Dessa forma, é perceptível que, entre os gregos, os atos pederastas fossem um aspecto comum no caminho de um rapaz rumo à idade adulta, e esses rapazes deveriam passar por um estágio pederasta a fim de tornarem-se adultos plenamente aceitos.

Essa temática é discutida também por Jeffrey Richards quando considera que:

A homossexualidade na Grécia relacionava-se estreitamente com a masculinidade, é importante captar essa perspectiva de modo a entender seu papel social. A relação sexual grega básica se dava entre um homem mais velho (erastes) $e$ um jovem (erro menos). O homem mais velho admirava o mais jovem por suas qualidades masculinas (beleza, força, velocidade, habilidade, resistência), e o mais jovem respeitava o mais velho por sua experiência, sabedoria e comando (RICHARDS, 1993, p. 138).

De acordo com os dois autores mencionados, a pederastia era, naquele contexto, um rito de iniciação daquela sociedade, que demarcava a passagem da infância para a adolescência, e desta para o mundo adulto, representando um sinal de honra.

Entretanto, as relações pederastas na Grécia pareciam estar estreitamente relacionadas com a masculinidade. Richards corrobora ainda afirmando que:

A sociedade grega desaprovava energicamente relações sexuais entre homens da mesma idade. Isto era considerado antinatural, pois significava que um dos homens adotava a posição passiva, traindo assim a masculinidade que dele requeria que assumisse o papel ativo. (RICHARDS, 1993, p. 138).

A relação entre dois adultos era, pois, motivo de crítica, especialmente voltada para os suspeitos de, à semelhança das 


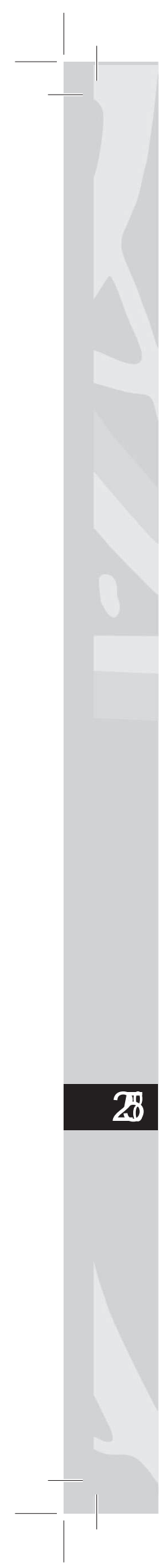

mulheres, exercerem função passiva no coito. Reprovava-se, pois, não a relação homoerótica em si, mas o indivíduo que, abrindo mão de sua superioridade masculina e de sua honra de cidadão, experimentasse o prazer à moda passiva e inferior, que caracteriza as mulheres.

No que concerne à sexualidade feminina na Grécia, há indícios de que houve uma comunidade formada por mulheres na ilha de Lesbos, da qual resultou a derivação Lesbianismo para referirse à homossexualidade feminina, e que tinha na poetisa Safo sua principal representante. Sobre esse assunto Bremmer afirma que "mesmo se, pelos padrões modernos, Safo devesse ser considerada lésbica, sua experiência deve ter sido muito diferente, vivendo como viveu em uma era diferente com diferentes tipos de sexualidade" (BREMMER, 1995, p. 50). Para esse autor, embora pudessem existir relações sexuais entre duas mulheres, geralmente uma adulta com outra mais jovem, seria anacronismo definir tal relação como Lesbianismo. A questão é complexa e cabem somente especulações.

\section{O entrelaçar da sexualidade em Roma}

Assim como na Grécia, no Império Romano as pessoas não eram classificadas como heterossexuais ou homossexuais. Essas expressões são inapropriadas para o período, uma vez que, para aqueles povos, esse tipo de relação ligava-se a papéis de atividade e passividade sexual. Essa ideia encontra sustentação em Feitosa, quando diz que "a pederastia constituía um pecado menor, desde que fosse a relação ativa de um homem livre com um escravo ou um homem de baixa condição" (FEITOSA, 2005, p. 99). Esse posicionamento é confirmado por Grimal quando afirma que: "os amores exteriores ao casamento eram vistos como amores pederásticos; o ato carnal marcando o "sangue" de quem a ele se submetia, todo o problema consistia em saber se essa marca era infligida a um ser que legitimamente podia recebê-la ou a alguém que devia permanecer intato" (GRIMAL, 1991, p. 122). 
De acordo com esses autores, é possível inferir que o ato pederástico em si não implicava necessariamente numa qualificação moral negativa, representava assim uma satisfação de um instinto natural. Porém, o ato de passividade, sim, era condenado. Dessa forma, a moral sexual ligava-se a um estatuto social. Um cidadão romano deveria sempre preservar o papel ativo, mas podendo ter relações pederásticas com pessoas de categoria inferior. Um senhor poderia ter relações com seus escravos, mas não poderia tê-las com um mesmo cidadão de sangue romano, o que pode ser confirmado por Robert "o caso era diferente quando o sangue romano não era ameaçado: o que era proibido com um cidadão era autorizado com um jovem escravo" (ROBERT, 1995, p. 223). A pureza de sangue deveria ser preservada, e o crucial era a manutenção dos papéis culturalmente definidos e socialmente sancionados de masculinidade e feminilidade.

Cabe ressaltar que, embora esse tipo de comportamento fora comum entre gregos e romanos, os papéis eram diferentes em cada uma das sociedades, já que os critérios morais dos romanos eram diferentes daqueles dos gregos.

A moral romana também variou em determinados períodos dessa sociedade. Há um consenso entre os autores analisados ao defenderem que, no final da república, a moral sexual evoluiu e uma maior liberdade sexual passou a reinar. Assim, a nova cultura fora colocada a serviço do prazer.

Nesse contexto, a busca dos prazeres passou a constituir a preocupação principal dos romanos no período de transição da república para o império. Robert confirma essa informação ao afirmar que "a civilização rústica com base no trabalho e na austeridade é sucedida por uma civilização urbana que oferecerá as tentações do prazer aos cidadãos" (ROBERT, 1995, p. 25). Para este autor, a modificação dos valores morais ocorridos em Roma, devese a uma mudança social, bem como a transformações de vida tanto econômicas quanto políticas. Diante do exposto, fica perceptível que a vida dos romanos passou a comportar vários prazeres, inclusive os 


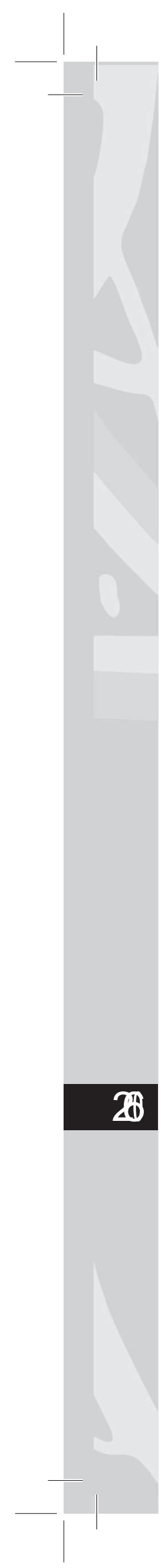

sexuais. Temas referentes à sexualidade tornaram-se, desse modo, muito comum, até em paredes das casas em Pompeia.

Essas discussões levam a inferir que a busca por prazer e por amores, não era, portanto, objeto de indiferença na antiga tradição Ocidental. Fato distinto do que ocorreu na Idade Média, já que, nesse período, houve uma crescente discriminação e reprovação quanto ao uso do corpo.

\section{$3 \mathrm{O}$ falo: entre o sagrado e o obsceno}

No tocante ao estudo da sexualidade clássica, uma abordagem sobre a sociedade fálica tem muito a contribuir. "Nesse contexto, o falo e a união carnal constituem objetos de especial interesse, por usar aparente simplicidade, que convida ao senso comum" (FUNARI, 2003, p. 317).

Há séculos o Falo ${ }^{3}$ fora símbolo de poder e glória. Nas culturas pagãs anteriores ao Cristianismo, o falo simbolizava um agente físico e espiritual e fazia alusão ao divino. Na sociedade contemporânea, qualquer imagem que faça alusão ao falo parece obsceno e indecente, contudo, na Antiguidade Cássica não o era. Pelo contrário, era considerada uma imagem sagrada, venerada como objeto de culto. A esse respeito Feitosa argumenta que "diferente da menção pudorada a ele destinada em sociedades contemporâneas, influenciadas por valores religiosos que atribuem conotações negativas ao sexo e aos elementos a ele associados, a representação do falo era frequente na sociedade romana" (FEITOSA, 2005, p. 45). A autora considera, dessa forma, que fatores culturais interferem e influenciam no olhar acerca de símbolos que façam alusão à sexualidade.

$\mathrm{Na}$ cultura grega, o culto ao falo também foi relevante. A representação monumental de pênis eretos, à entrada de edifícios públicos, nomeadamente templos e teatros, é bem reveladora da

\footnotetext{
${ }^{3}$ De acordo com Funari (2003), Falo refere-se à representação simbólica do pênis.
} 
importância simbólica que era atribuída ao pênis e à masculinidade. O altar fálico de Dionísio, na ilha de Delfos, é um dos exemplos mais marcantes dessa representação monumental.

Após a queda do império romano, e a crescente influência do Cristianismo, o culto ao falo foi diminuído, e essa manifestação passou a representar conotações ligadas ao pudor e ao pecado. A representação do pênis foi, pois, remetida a uma ação repressiva.

$\mathrm{O}$ aporte espiritual do Cristianismo freou e moderou o embrutecimento de um império desregrado por vícios pagãos. Dessa forma, o Cristianismo interveio, representando uma mutação cultural e mental. Os novos cristãos procuraram evitar a participação em atos de vida social pagã, cujo espírito se opunha aos preceitos de sua religião. A sexualidade, nesse sentido, passou a ser vista sob um novo prisma, uma vez que os cristãos passam a fazer outra leitura sobre tal questão.

\section{Mutações de olhar: o Cristianismo rompendo estruturas}

O Cristianismo apresenta-se então como uma doutrina capaz de responder às inquietações e angústias do homem da alta Idade Média, afligido pelos escombros de um império que deixava as cidades em ruínas e o antigo modo de vida em decomposição. A Igreja, assim, passou a desempenhar, nesse período, o papel de órgão regulador da vida moral e espiritual, utilizando-se desse deslize em proveito próprio.

Nesse cenário, a sexualidade, o corpo, por meio da renúncia dos prazeres da carne, passou ao controle da temporalidade eclesiástica.

A respeito disso, Jaques Le Goff afirma que:

Para a opinião comum, a antiguidade tardia marcou uma virada decisiva nas concepções e nas práticas da sexualidade no Ocidente. Depois de um período antigo-greco-latino em que a sexualidade e o prazer carnal foram valores positivos e em que reinou uma grande liberdade sexual vieram instalar-se a geral condenação da sexualidade e a estrita regulamentação

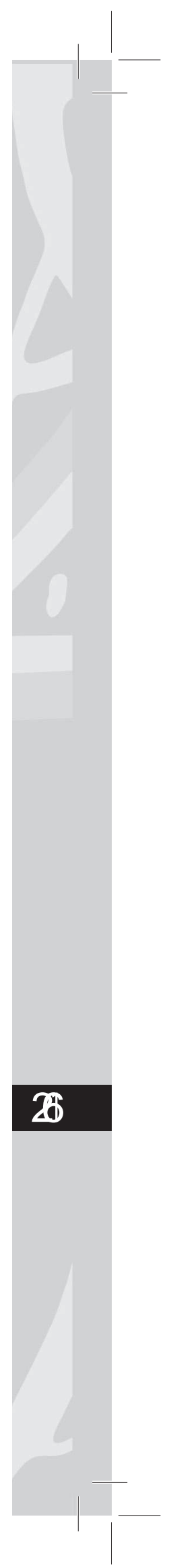


do seu exercício. O principal agente desta inversão foi o Cristianismo (LE GOFF, 1994, p. 157).

Jeffrey Richards, sobre esse assunto, corrobora ao dizer que "a atitude em relação ao sexo é típica da igreja cristã como um todo. Pois a cristandade foi, desde seus primórdios, uma religião negativa quanto ao sexo" (RICHARDS, 1993, p. 34).

Foi a Igreja que tomou a iniciativa de especificar quais atos sexuais poderiam ser praticados, além de regular onde, quando e com quem o sexo poderia ter lugar, por isso se tornara a força dominante na vida moral e espiritual das pessoas. Com isso, além dos cultos e das cerimônias praticados pelo paganismo, o sexo foi o maior entrave entre este e a Igreja Católica.

Sobre o paganismo Mário Curtis considera:

Oscristãos, entretanto, procuraram evitar a participação
em atos de vida social pagã, cujo espírito se opunha
frontalmente aos preceitos de sua religião. Assim, por
exemplo, o jogo, o luxo, os espetáculos de gladiadores,
etc., eram condenados pelas principais figuras da Igreja
pré-constantina. (GIORDANI, 2002, p. 360).

No tocante ao sexo, a Igreja Católica, assim, desde os primórdios foi uma religião negativa, pois os pensadores encaravam a prática sexual, na melhor das hipóteses, como um mal necessário, somente indispensável para a reprodução humana. Para tanto, o corpo deveria ser privado de qualquer atividade sexual: o beijo, o abraço, o ato sexual, o toque de mãos e até a visão do próprio corpo foram proibidos. "Assim, é possível afirmar que o corpo sexuado na Idade Média é majoritariamente desvalorizado, as pulsões e o desejo carnal, amplamente reprimido" (LE GOFF, 2006, p. 41).

Acerca das relações sodomitas ${ }^{4}$, praticamente todos os teólogos são unânimes na condenação do comportamento homossexual,

\footnotetext{
${ }^{4}$ Segundo Richards (1993), utiliza-se este termo para designar indivíduo que pratica relações sexuais com pessoas do mesmo sexo. Utiliza-se também para denominar o indivíduo que pratica a cópula anal.
} 
considerando-o uma das consequências do pecado original e um claro desvio dos propósitos do criador. Dentro dessa problemática, Franco Junior salienta que:

O casamento cristão combatia especialmente a homossexualidade, o pior pecado sexual possivel, por visar apenas o prazer e não á procriação como Deus determinara ao primeiro casal: "sejam fecundos e multipliquem-se" (Gêneses 1,28). Outra passagem bíblica, muito citada pelo clero medieval, comprovava o horror ao homossexualismo difundido em Sodoma e Gomorra, cidades por essa razão, destruídas por Deus com enxofre e fogo (GÊENESIS apud FRANCO JÚNIOR, 2006, p. 127).

Numa visão panorâmica, identifica-se de acordo com o autor, a reprovação quanto aos atos homossexuais. Sua origem está impregnada no primeiro livro da Bíblia, o Gênesis. No relato bíblico, Deus criara o ser humano, homem e mulher para se unirem e procriarem, daí supõe-se, portanto, uma heterossexualidade universal. O contato erótico entre pessoas do mesmo sexo foi logo associado ao pecado de Sodoma, que despertou a ira divina e o castigo arrasador. "A noção de pecado contranatura, que iria se dilatar na Idade Média com a extensão do conceito de sodomia assim proscrevia a homossexualidade, a sodomização da mulher, o coito dorsal e o coito de Andrômaca - com a mulher sobre o homem" (LE GOFF, 1994, p. 160).

Complementando esta discussão, Vainfas declara que, "sodomia, fornicação e luxúria eram quase sinônimos, ou podia sê-lo na teologia moral da Alta Idade Média, apesar do permanente destaque que sempre se deu ao coito anal como ato sodômico por excelência" (VAINFAS, 1989, p. 161).

O controle e o poder da Igreja nascente estenderam-se também ao casamento, por meio de regulamentações e limitações 


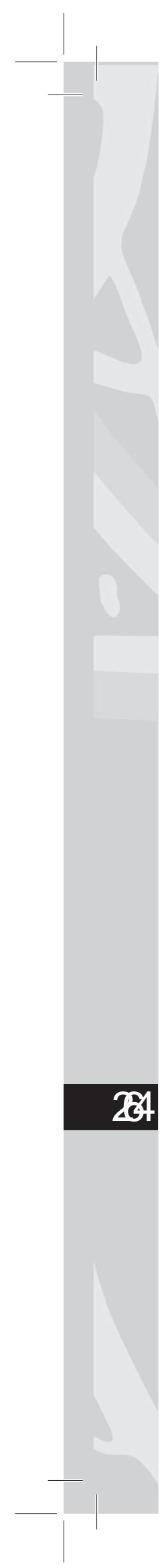

das relações sexuais entre casais, já que a sexualidade, segundo os ensinamentos cristãos, era dada às pessoas exclusivamente com o objetivo de procriação. Desta forma, a monogamia e a virgindade para as mulheres passam a ser valorizadas como símbolo de virtude. "A vida sexual ideal passou a ser inexistente. A Virgindade tornouse um grande valor, seguindo os modelos de Cristo e sua mãe" (FRANCO JÚNIOR, 2006, p. 127).

Como meio de controle das práticas consideradas ilícitas e desaprovadas pela Igreja, a prática da confissão teve papel relevante. A confissão da verdade se inscreveu no cerne dos procedimentos de individualização pelo poder, sendo uma das técnicas altamente valorizadas para produzir a verdade. Segundo Foucault "Desde a Idade Média, pelo menos, as sociedades ocidentais colocaram a confissão entre os rituais mais importantes de que se espera a produção da verdade" (FOUCAULT, 1980, p. 58). Entende-se assim, que a prática da confissão está infiltrada por uma relação de poder.

O quarto século da era cristã foi marcado pelo pensamento teológico de Santo Agostinho, Bispo de Hipona. Este não só construiu as bases para a sistematização da teologia cristã em sua obra, como reformulou sobre o corpo e a sexualidade. Sua obra contém as bases da teologia cristã. Nesse sentido, Hilário Franco Junior faz uma colocação importante:

O grande nome da Patrística e uma das figuras que sem dúvida, maior influência exerceu por toda a Idade Média, foi Santo Agostinho. Para acompanhar seu pensamento, é preciso lembrar que para ele as verdades da fé não podem ser demonstráveis pela razão, mas esta pode confirmar aquela: "Compreender para crer, crer para compreender". Essa premissa alicerçava suas quatro idéias de maior alcance histórico, duas destruindo objeções da filosofia pagã ao Cristianismo e duas outras que seriam muito importantes para o medievo (FRANCOJÚNIOR, 2006, p. 106). 
A análise de BARK, sobre esse assunto, também caminha na mesma direção:

Foi Agostinho de Hipo, porém, quem aceitou o desafio de sua época no mais alto plano intelectual e fez a defesa do aparecimento da nascente cultura cristã em sua poderosa filosofia da história. Viu que era necessário não só responder aos motejos dos pagãos, mas também impedir a identificação popular da prosperidade do Cristianismo com a prosperidade de Roma (BARK, 1979, p. 106).

Para se tratar do papel da Igreja em questões morais, centradas na sexualidade, foi Santo Agostinho aliado a outros "pais da Igreja" que marcaram a ruptura da alma em relação ao corpo. Nessa acepção, a sexualidade recebe um peso que não tivera até então.

A partir da influência de Agostinho, o novo cristão seguirá um caminho totalmente alheio aos barulhos, aos desejos e tormentos da carne.

\section{Os concílios e a nova mentalidade}

Considerando os concílios como suporte material e espiritual, responsáveis por discutir e decidir sobre questões tanto administrativas quanto de fé, é significativamente atribuível a eles uma relação de poder. A esse respeito, Foucault afirma que "em face de um poder, que é lei, o sujeito que é constituído como sujeito - que é "sujeitado"- é aquele que obedece" (FOUCAULT, 1980, p. 82). Verifica-se, assim, de acordo com Foucault, o poder como agente ou órgão legislador, podendo impor uma forma de submissão sobre o outro.

Durante a Idade Média, os concílios, bem como, os sínodos se tornaram um importante utensílio de organização e afirmação do poder da Igreja. No âmago da sociedade, funcionou como local singular para os assuntos religiosos e doutrinários, a definição da 
liturgia, resolução de conflitos políticos, assim como resposta a outras questões religiosas, administrativas, morais e financeiras.

No âmbito dessa discussão, Hilário Franco Junior é enfático ao dizer que:

\begin{abstract}
As questões de doutrina eram debatidas, sobretudo nos concílios ecumênicos, que congregavam bispos de todas as regiões, expressando a universalidade da Igreja. O primeiro, por exemplo, celebrado em Niceia em 325, visava fundamentalmente se posicionar diante do arianismo, corrente para a qual Cristo, por ter sido criado pelo pai, não era da mesma substância dele, sendo-lhe inferior, logo, como conclui o concilio, tal ideia contraria o dogma da trindade, daí ter sido condenada (FRANCO JÚNIOR, 2006, p. 68).
\end{abstract}

O mesmo autor considera que todos os concílios ecumênicos foram de grande importância e tiveram papel fundamental na definição e na estruturação da Igreja. "Sua cronologia indica o próprio ritmo de organização da Igreja: dois no século IV, dois no século VI, um no VIII, um no IX, três no XII, três no XIII, um no XIV, dois no XV, dois no XVI" (FRANCO JÚNIOR, 2006, p. 69).

\title{
Considerações finais
}

Conforme a literatura investigada, percebeu-se que a sexualidade passou por várias transformações no limiar do tempo. Este trabalho visou compreender qual a postura do Cristianismo com relação a ela, considerando o período proposto, ou seja, transição entre Antiguidade Clássica e Medievo. Percebeu-se, desse modo, que o Cristianismo rompeu com os preceitos clássicos e acabou por determinar uma nova postura moral acerca da sexualidade.

É necessário ressaltar que muitas de nossas mentalidades e muitos de nossos comportamentos foram concebidos na Idade Média. Isso é válido também para as atitudes em relação ao corpo. É de fato na Idade Média que se instala esse elemento fundamental 
de nossa identidade coletiva, que é o Cristianismo, atormentado pela questão do corpo. O que ocorreu nesse período teve consequências de longo alcance para as idades posteriores. Daí a relevância deste estudo.

No tocante à mudança de postura a respeito da sexualidade, a pesquisa revelou, os inegáveis meios e estratégias utilizados pela Igreja como forma de romper com a sexualidade clássica, agora, vista sob o prisma do erotismo, determinado pelos teólogos da Igreja. Buscamos desta forma, apreender conotações do que seria erótico em sociedades diferentes.

O Cristianismo veio a ser erigido em torno de princípios a partir de perspectiva transcendente da vida. Nesse viés, o lugar ocupado pelo corpo e pela sexualidade deslocou-se do plano positivo em que se encontrava, especialmente pela significação que tinha nos rituais religiosos pagãos, para o âmbito negativo do pecado.

A utilização da importância dos Concílios nessa abordagem e a constante contribuição dos denominados "Pais da Igreja" justificouse pela importância destes para a estruturação e a legitimidade para a religião nascente, que precisava de um importante embasamento para que pudesse expandir e determinar o seu poderio; poderio esse que se estendera a todos os níveis daquela sociedade.

\section{REFERÊNCIAS}

BARK, Willian Carrol. Origem da Idade Média. Rio de Janeiro: Zahar, 1979.

BREMMER, Jean (m). (Org.). De Safo a Sade: momentos da História da sexualidade. São Paulo: Papirus, 1995.

FEITOSA, Lourdes Conde. Amor e Sexualidade: o masculino e o feminino em grafites de Pompeia. São Paulo: Annablume: 2005. 
FOUCAULT, Michel. História da Sexualidade I: a vontade de saber. $3^{\text {a }}$ ed. Rio de Janeiro: Graal, 1980.

FOUCAULT, Michel. História da Sexualidade 2: o uso dos prazeres. Rio de Janeiro: Graal, 1984.

FRANÇA, Junia Lessa; VASCONCELOS, Ana Cristina de. Manual para Normalização de Publicações Técnico-Científicas. Belo Horizonte: Ed. UFMG, 2007.

FUNARI, Pedro Paulo A. A Vida Cotidiana na Roma Antiga. São Paulo: Annablume, 2003.

GIORDANI, Mário Curtis. História de Roma: Antiguidade Clássica II. Petrópolis: Vozes, 2002.

GRIMAL, P. O Amor em Roma. São Paulo: Martins Fontes, 1991.

LE GOFF, Jacques. O Imaginário Medieval. Portugal: Estampa, 1994.

LE GOFF, Jacques; TRUONG, Nicolas. Uma História do Corpo na Idade Média. Rio de Janeiro: Civilização Brasileira, 2006.

REIS, José Carlos. Escola dos Annales: a inovação em História. São Paulo: Paz e Terra, 2000.

RICHARDS, Jeffrey. Sexo, Desvio e Danação: as minorias da Idade Média. Rio de Janeiro: Jorge Zahar, 1993.

ROBERT, Jean Noel. Os Prazeres em Roma. São Paulo: Martins Fontes, 1995.

VAINFAS, Ronaldo. Trópico dos Pecados: moral, sexualidade e inquisição no Brasil colônia. Rio de Janeiro: Campus, 1989. 